\title{
A POSSIBILIDADE DEMOCRÁTICA DAS POLÍTICAS EDUCACIONAIS
}

\author{
Mário José Puhl ${ }^{1}$ \\ Alexandre José Krul ${ }^{2}$
}

\begin{abstract}
Resumo
Este trabalho aborda a temática da instituição e da efetivação da educação compreendida como uma política pública de caráter social, através da participação dos indivíduos e da sociedade nos diferentes espaços públicos articuladores desta ação. Uma elaboração sustentada na pesquisa bibliográfica e documental com um olhar direcionado à educação de caráter republicano, a qual intenta debater e afirmar a participação do conjunto das pessoas nos espaços públicos democráticos, com vistas à efetivação de um direto da cidadania. Defende-se uma educação de caráter público, universal, gratuita e laica, instituída pelos mecanismos democráticos e republicanos, pela participação direta e indireta dos cidadãos e cidadãs. A participação na formulação do currículo escolar, independentemente do nível de educação, democratiza a escola como lócus formativo e o seu currículo. Um currículo democrático contribui na formação e educação democrática e também para uma sociedade democrática.
\end{abstract}

Palavras-chave: Educação. Cidadania. Participação. Política pública.

\section{THE DEMOCRATIC POSSIBILITIES OF EDUCATIONAL POLICIES}

\begin{abstract}
This paper deals with the theme of institution and the effectiveness of education understood as a public policy of social character, through the participation of individuals and society in the different public spaces that articulate this action. A sustained elaboration in the bibliographical and documentary research with a view directed to the education of republican character, which tries to debate and affirm the participation of all the people in the democratic public spaces, with a view to the realization of a direct citizenship. An education of a public, universal, free and secular nature, instituted by democratic and republican mechanisms, is advocated for the direct and indirect participation of citizens. Participation in the formulation of the school curriculum, regardless of the level of education, democratizes the school as a formative locus and its curriculum. A democratic curriculum contributes to democratic education and training, and also to a democratic society.
\end{abstract}

Keywords: Education. Citizenship. Participation. Public policy. 


\section{INICIANDO O DIÁLOGO}

Com o advento da Constituição Federal de 1988, a educação brasileira é definida como uma política social. Esta possui como intencionalidade de proporcionar o bem estar e a justiça social, conforme estabelecido no artigo 193 da Carta Magna. Uma política social, instituída pelo Estado, que tem seu sentido de ser na efetivação de programas, cujo acesso é de caráter universal, gratuito e laico. É a perfectibilização de um direito fundamental instituído por uma sociedade humana.

O presente trabalho, embasado na literatura teórica e documental atinente à participação social na formulação e execução de políticas públicas, com um olhar direcionado à educação de caráter republicano, intenta debater e afirmar a participação do conjunto das pessoas nos espaços públicos democráticos. Dentre os espaços fundantes da democracia direta estão os conselhos setoriais, a escola, o currículo, as assembleias e as conferências, que por sua vez não prescindem de cidadãos e cidadãs aptos e desejosos ao exercício pleno da cidadania.

\section{CONDIÇÕES DE POSSIBILIDADES PARA A PARTICIPAÇÃO}

Afirmar a existência de direitos fundamentais, individuais e ou coletivos, independentemente de sua dimensão dialoga com a questão fundamental do que torna possível, viável ou mais razoável a vida humana em sociedade e as possibilidades de sua continuidade democrática, respectivamente. Entende-se imprescindível a afirmação e a concretização de direitos humanos como condição de existência de uma sociedade efetivamente democrática e plural. Para Bobbio, o debate sobre os direitos humanos não é tanto filosófico, sobre seus fundamentos teóricos, mas jurídico e político, pois não se busca

\footnotetext{
[...] saber quais e quantos são esses direitos, qual é sua natureza e seu fundamento, se são direitos naturais ou históricos, absolutos ou relativos, mas sim qual é o modo mais seguro para garanti-los, para impedir que, apesar das solenes declarações, eles sejam continuamente violados. (BOBBIO, 2004, p. 25).
}

A dinâmica de construção da sociedade moderna ocidental está alicerçada nos pressupostos de que a pessoa possui direitos fundamentais como condição necessária para a sua existência social, política, cultural e econômica, dentre outras perspectivas. Estes direitos são caracterizados como naturais ou civis. Os direitos, entendidos como naturais, referemse àqueles que são inatos à condição humana, pelo simples fato de a pessoa existir, como o direito à vida, à liberdade, à consciência e à dignidade. A tese dos direitos naturais remonta à teoria do direito subjetivo natural, criada pelo filósofo inglês Guilherme de Ockham (1999; 1988), definido como o direito à vida, à consciência e aos bens materiais e espirituais necessários à garantia da vida e da consciência, independentemente de sua condição social ou econômica. Igualmente estabelece como direito natural o da resistência dos súditos ao governante, exercido pelo indivíduo ou sociedade, quando aquele não garante a preservação dos direitos fundamentais. A teoria do direito natural é posteriormente retomada pelo filósofo inglês Locke (2002), no final do século XVII e início do século XVIII. Para este pensador o ser humano possui, naturalmente, o direito à vida, à liberdade, à segurança e aos bens necessários para a preservação dos dois direitos anteriores. Os bens, compreendidos 
como a propriedade privada e outros, deveriam ser adquiridos através do trabalho. O filósofo liberal legitima o trabalho como meio adequado para a obtenção da propriedade privada na condição de um direito natural, pois Deus, para fazer o mundo trabalhou e o fruto legítimo do seu trabalho, sua propriedade, foi dado à uma de suas criaturas, o homem. Este, criado à imagem e semelhança do seu criador, também deveria trabalhar para conseguir os bens, pois Deus instituiu, durante a criação do homem e do mundo, o direito à propriedade privada como fruto legítimo do trabalho. Sendo de origem divina, ela é um direito natural de cada pessoa.

Rousseau $^{3}$ (2013), por seu turno, entende que os direitos à propriedade, à segurança, à liberdade, são direitos civis, visto que foram instituídos, mediante um contrato social, um acordo conjunto, pela sociedade humana. São direitos decorrentes da vida em sociedade e de suas formas de organização.

As teses de que as pessoas possuem direitos naturais, que antecedem à qualquer forma de sociedade política, do Estado, são fortalecidas pelos movimentos revolucionários ocorridos na Europa como a inglesa (1644-1688), através da qual a Inglaterra passou da monarquia absoluta para uma monarquia parlamentar e a francesa, de 1789 que pauta-se pelos ideias republicanos de organização política da sociedade. Anteriormente, em 1776, ocorreu a revolução americana, mas sintonizada com os ideais políticos iluministas. As revoluções, americana e a francesa, são precedidas por declarações formais de direitos naturais e civis. A Declaração de Virgínia e a Declaração Francesa afirmam que as pessoas possuem, primeiramente, direitos naturais e, posteriormente, direitos civis, sendo os primeiros condição para o exercício dos posteriores ${ }^{4}$, de caráter inalienável e imprescritível.

Uma das dimensões ${ }^{5}$ dos direitos humanos é a civil e a política na qual inscrevem-se a liberdade de expressão e de consciência. Estas duas perspectivas, mas essencialmente a da expressão afirma o direito da isagoria, isto é, do direito de expor e debater publicamente as ideias e fazer parte das deliberações públicas, dos assuntos que dizem respeito ao conjunto da sociedade, como é o caso da educação. Pari passu à este direito está o da isonomia ${ }^{6}$, isto é, a igualdade de todos perante a lei e igualdade civil e política.

A efetivação do direito de isagoria realiza-se na medida em que são instituídos espaços de participação e de deliberação públicos e de radicalidade democrática. A possibilidade de participação e de decisão requer a existência de mecanismos (meios) efetivamente democráticos para a sua realização. Estes possíveis meios de participação e deliberativos serão abordados mais adiante, neste texto.

A educação compreendida como um direito individual civil, com uma dimensão social, requer a garantia do Estado a todos os indivíduos que fazem parte do mesmo. É um direito cuja efetivação pode ser requerido por parte da cidadania frente ao poder público. É um direito oriundo dos ideais iluministas do século XVIII, dos movimentos sociais e sindical. É um direito da pessoa em relação à sociedade e ao Estado, o que pode ser visto na Constituição Federal de 1988, que assim afirma:

Art. 205. A educação, direito de todos e dever do Estado e da família, será promovida e incentivada com a colaboração da sociedade, visando ao pleno desenvolvimento da pessoa, seu preparo para o exercício da cidadania e sua qualificação para o trabalho. (BRASIL, 2002, p. 123). 
Este artigo constitucional define que a educação é um direito de todos os brasileiros e de todas as brasileiras independentemente de sua situação social, econômica, religiosa, etária ou de qualquer outra forma. Segundo, constitui um crédito do indivíduo perante duas instituições sociais fundantes da sociedade: o Estado e a família. Cabe à elas a oferta, o acesso, a permanência de todos, com a colaboração da sociedade, visto que é dela que o Estado arrecada seus tributos para prover a oferta do ensino público, universal, gratuito e laico.

Uma das intencionalidades educacionais manifesta nesta norma jurídica e deste direito estabelecido, é a do "[...] preparo para o exercício da cidadania" (ibid.), o qual poderá ser realizado pela participação nos debates e deliberações pertinentes à educação tanto no âmbito da escola, da universidade quanto do Estado. Uma intenção expressa de forma mais evidente no princípio do ensino brasileiro, que sustenta o ensino como um direito fundamental da cidadania, expressa no inciso VI do artigo 206 da Constituição Federal ${ }^{7}$ : "gestão democrática do ensino público, na forma da lei".

Seguindo a linha de pensamento do Teixeira (1998) a participação política dos cidadãos foi construída na Europa, no final do século XIX, em um contexto de democracia competitiva, na luta pelo direito ao sufrágio universal e livre, da possibilidade da criação de partidos políticos, nas lutas sindicais por melhores condições de trabalho e outros direitos humanos.

Durante o século XVIII e XIX são criadas ou reconfiguradas, especialmente na Europa e nos Estados Unidos da América as principais instituições sociais como a escola, a igreja, o Estado, a lei, a família, o trabalho, as organizações de classe e de categorias de trabalhadores, os partidos políticos. Estas instituições tem a atribuição de socializar as pessoas, dar identidade política e social, criar a noção e prática do pertencimento, criar e assegurar o status da cidadania, constituir referência e reconhecimento, contribuir na humanização, internalizar a cultura, as normas e organizar a vida em sociedade. Cabe algumas destas instituições a representação da sociedade perante o Estado e a forma de acesso aos espaços formais de poder do Estado, que são os partidos políticos. Eles desempenham o papel de articuladores sociais, organizam a cidadania conforme suas ideologias e projetos de poder e competem pelo poder institucional. Aos sindicatos de trabalhadores cabe a tarefa de organizar os trabalhadores e lutar pela melhoria das condições de trabalho e dos salários, basicamente. Isto é, estas duas organizações sociais, sindicato e partido, são organizações que representam uma parte da sociedade e lutam pelos espaços de poder e demandam novas ações públicas.

Com a crise deste modelo de representação social, o surgimento de novos conflitos sociais, econômicos, culturais e ambientais, da crescente demonstração de que várias pautas e necessidades não estavam incluídas nas propostas, seja dos partidos ou dos sindicatos, são demandadas novas formas de participação, que são mais amplas e contestadoras ${ }^{8}$. São movimentos sociais que pressionam para a mudança das instituições representativas, apresentam novas pautas, demandam a formulação e execução de novas políticas públicas, requerem novos mecanismos de participação, a retomada e afirmação dos espaços públicos, questionam o modelo civilizatório existente e pugnam por uma sociedade democrática, livre e plural. 
Além da apresentação de novas demandas à sociedade e ao Estado novas formas de resolução dos problemas são criadas. Novos arranjos institucionais são instituídos, nos quais participam a sociedade e o Estado. Um exemplo de formação de outro centro de poder decisório refere-se à forma como é corrigido o valor do salário mínimo nacional. Em 2005 foi criado um Grupo de Trabalho integrado pelas centrais sindicais de trabalhadores, sindicatos patronais, os ministérios da Previdência, Trabalho e Planejamento, com a atribuição de elaborar um programa de valorização real do salário mínimo. A partir da vigência do programa de elevação do salário mínimo acima da inflação, ou seja, com ganhos reais, pois conjuga critérios de correção do valor deste o índice da inflação medida no período e o crescimento econômico registrado. É um acordo estabelecido cuja vigência está prevista até o ano de 2023. É um mecanismo que associa a remuneração salarial com o desenvolvimento do país, construído com a participação cidadã neste novo centro decisório. É uma política pública que articula democracia direta, participação e redução das desigualdades sociais, visto que o aumento real do salário mínimo constitui uma das formas de distribuição de renda no país.

$\mathrm{Na}$ área da educação ocorreram muitas atividades que contaram com a participação da sociedade, professores, Universidades, escolas, centros de pesquisa, movimentos sociais, sindicatos, etc. nas conferências realizadas pelo país e finalizadas na Conferência Nacional da Educação. Os projetos fundamentais foram decididos e posteriormente transformados em políticas públicas, como a reforma universitária, as alterações do Programa Universidade para Todos (ProUni), o plano de reconstrução e expansão das universidades federais, o piso nacional do magistério e o debate para a aplicação de um valor anual correspondente a $10 \%$ do Produto Interno Bruto (PIB) na educação. Igualmente, fruto da mobilização da sociedade brasileira e votação no Congresso Nacional, são destinados $50 \%$ dos recursos financeiros advindos da exploração do petróleo localizado no pré-sal para a educação brasileira, em todos os níveis de ensino.

\section{HORIZONTAIS DA POLÍTICA SOCIAL}

Em termos gerais, as políticas sociais podem ser caracterizadas em três perspectivas teóricas e práticas diferentes, mas não em sentido antagônico: políticas assistenciais (de caráter compensatórias e garantia de um mínimo de dignidade), políticas sócio-econômicas (relacionadas com programas e ações de transferência e distribuição de renda, de crédito, macro e micro-econômicas, habitacionais, de saneamento, etc.) e políticas participativas, cada qual com a sua especificidade e alcances.

As três dimensões de políticas estabelecem uma relação mútua, se inter-relacionam, mas cada qual possui a sua singularidade. A política social na perspectiva participativa, emancipatória, está ancorada na tese da sociedade organizada, na democracia participativa, seja por parte das pessoas diretamente envolvidas em um determinado assunto ou de toda a sociedade. Ela não trabalha com a manipulação dos indivíduos, mas os entende e os situa como sujeitos coparticipantes e co-decisores.

Referir-se às políticas públicas, instituídas com a participação popular, é tratar da relação da cidadania com o Estado. O Estado com sua dinâmica organizativa e de funcionamento, suas estruturas e os mecanismos de participação social, influenciam na 
formulação e execução de políticas sociais, pode criar mecanismos que viabilizam a participação de sua população. A capacidade e as possibilidades efetivas de participação constroem uma qualidade política na população, afirmam Weffort (1985) e Bobbio (2011). Estabelecem-se relações mútuas de cidadania com o Estado, pois da qualidade política da população dependem a qualidade das políticas públicas e a qualidade política do Estado, por sua vez fortalecerá e promoverá uma cidadania efetiva e participativa. Uma qualidade cidadã produzirá políticas públicas qualificadas e republicanas e somente um Estado democrático, republicano e com canais reais de participação social executará programas cidadãos e promoverá democracia e participação. Cidadãos democráticos constroem relações democráticas e um Estado democrático e este fortalecerá a cidadania afirmativa e os mecanismos reais, sustentam os mesmos autores.

Disto decorre uma pergunta. Quem são os destinatários das políticas públicas, especialmente as políticas sociais? Responder esta indagação requer alargar o horizonte compreensivo das formas como são constituídas as políticas sociais públicas e o conteúdo de suas propostas. A participação direta da população na formulação de políticas sociais como a educação, muda o seu conteúdo e a sua forma de efetivação, pois cria um novo espaço decisório, outro centro decisório, que igualmente é educativo em si mesmo, que conjuntamente com os poderes legislativo e executivo, democratizam a ação política e o Estado, pois conjugam a democracia direta com a representativa, sem se anular mutuamente. Integra a cidadania no espaço público

[...] um espaço vital, necessário para cada indivíduo construir, consciente e criativamente, sua identidade, seus projetos e seus sonhos, enfim, sua dignidade se sujeito racional, a partir de direitos fundamentais socialmente reconhecidos. $\mathrm{O}$ público diz respeito às condições externas, comuns a todas as pessoas, e que permitem a efetivação da trajetória de cada ser humano, respeitadas as diferenças e as especificidades constitutivas da personalidade individualizada. [...] As condições econômicas das quais dependem a realização plena do ser humano integram, sob esse entendimento, o conteúdo do referente espaço público. (CORRÊA, 2010, p. 27-28).

O novo centro de decisões, o espaço público, incide sobre o caráter e os investimentos públicos e á capaz de alterar a lógica da distribuição da renda socialmente gerada e contribuir para a democratização do Estado, seus mecanismos e da economia. Sem a democratização do Estado e da economia, não há políticas públicas efetivamente democráticas. Distribuir a renda sem socializar e democratizar a política pode gerar certo tipo de paternalismo, que é nocivo à afirmação da autonomia da subjetividade e das organizações sociais. Socializar a política, sem alterar a lógica da produção, distribuição e consumo da riqueza, pode promover o desalento e o desencanto com a participação social.

Um espaço que é permeado por legítimos conflitos de interesses, manifestos nos desejos de dimensão política, econômica, cultural, dentre outras, mas que devem ser encaminhados e deliberados na seara da política republicana. É no espaço público, republicano, que os conflitos, debates e deliberações devem ser encaminhados. São as compreensões divergentes quanto ao conteúdo e à forma das políticas públicas que serão objeto de análise e de deliberação, pois estão permeadas pelas relações de poder, geradas no espaço público porque requerem a "existência do espaço público e da pluralidade, da diversidade de opiniões e de manifestação, na qual o indivíduo singular se revela a si próprio 
e aos outros, através da fala, buscando a persuasão, o convencimento pelo melhor argumento, afirma Schio. (2006, p. 197).

O Estado democrático está alicerçado e embasado na soberania popular, na cidadania organizada que o funda. A cidadania formula políticas sociais através dos instrumentos de participação previstos na Constituição $\mathrm{Federal}^{9}$, pois como afirma o parágrafo único do artigo primeiro que todo "[...] poder emana do povo, que o exerce por meio de representantes eleitos ou diretamente". (BRASIL, 2002, p. 13). Na Lei de Responsabilidade Fiscalhá dispositivos claros que requerem a participação direta dos indivíduos e da sociedade na gestão dos negócios públicos.

\footnotetext{
Art. 67.0 acompanhamento e a avaliação, de forma permanente, da política e da operacionalidade da gestão fiscal serão realizados por conselho de gestão fiscal, constituído por representantes de todos os Poderes e esferas de Governo, do Ministério Público e de entidades técnicas representativas da sociedade, visando a:

I - harmonização e coordenação entre os entes da Federação;

II - disseminação de práticas que resultem em maior eficiência na alocação e execução do gasto público, na arrecadação de receitas, no controle do endividamento e na transparência da gestão fiscal;

III - adoção de normas de consolidação das contas públicas, padronização das prestações de contas e dos relatórios e demonstrativos de gestão fiscal de que trata esta Lei Complementar, normas e padrões mais simples para os pequenos Municípios, bem como outros, necessários ao controle social;

IV - divulgação de análises, estudos e diagnósticos. (BRASIL, 2000).
}

Complementando os dispositivos legais, em nível federal vigentes no país, acrescentam-se as previsões estabelecidas no Estatuto da Cidade, definido pela Lei Federal $10.257 / 2001$, que em seu artigo $2^{\circ}$ e seus dois primeiros incisos, para a consecução das funções sociais da cidade, há que se garantir o acesso aos serviços públicos e a efetivação da gestão democrática das cidades através da participação da população.

Art. 2o A política urbana tem por objetivo ordenar o pleno desenvolvimento das funções sociais da cidade e da propriedade urbana, mediante as seguintes diretrizes gerais:

I - garantia do direito a cidades sustentáveis, entendido como o direito à terra urbana, à moradia, ao saneamento ambiental, à infra-estrutura urbana, ao transporte e aos serviços públicos, ao trabalho e ao lazer, para as presentes e futuras gerações;

II - gestão democrática por meio da participação da população e de associações representativas dos vários segmentos da comunidade na formulação, execução e acompanhamento de planos, programas e projetos de desenvolvimento urbano. (BRASIL, 2001).

Machado (1997) destaca a importância da articulação entre os projetos individuais e os projetos coletivos, que se manifestam nos espaços públicos. A articulação, entre projetos pessoais e societários possibilitará à cada pessoa, no seu cotidiano, a participação ativa na sociedade e assumir responsabilidades pertinentes aos interesses e temas de toda a sociedade, formando uma ética da responsabilidade. Esta articulação de projetos também deveria estar presente na educação, na qual uma das tarefas é a de "[...] prover os indivíduos de instrumentos para a plena realização desta participação motivada e competente, desta 
simbiose entre interesses pessoais e sociais, desta disposição para sentir em si as dores do mundo". (MACHADO, 1997, p. 47).

Este mesmo autor sublinha que os projetos coletivos, independentemente da área que forem, como um Plano Educacional, não necessitam serem detalhados em pormenores, pois poderiam tolher a capacidade criativa de cada unidade escolar, retirando-lhe a autonomia. Seria adequado e razoável que os planos se constituíssem em uma carta de princípios gerais, de valores fundamentais, referenciais gerais, elaborados com a participação social (individual e coletiva). Cita como referência desta tese a Lei de Bases do Sistema Educativo de Portugal a qual possui uma preocupação em valorizar o ser humano, o indivíduo, ao mesmo tempo em que estabelece valores para as relações intersubjetivas como a tolerância, a solidariedade, a democracia e a cidadania.

Por analogia, da relação estabelecida entre os projetos coletivos e individuais, tornase possível relacionar a escola como uma unidade educacional, um espaço singular, com sua força própria com as políticas educacionais gerais, em nível de federação. Igualmente, em nível mais micro, as relações que cada aluno e aluna e cada professor e professora estabelecem com a escola.

\title{
EDUCAÇÃO E PARTICIPAÇÃO
}

A educação, algo tipicamente humano, constitui-se num ato de intervenção no mundo. Um desejo por transformações na sociedade, nas mais variadas áreas seja ou no sentido de sua manutenção e conservação da ordem vigente, compreende Freire (2011). Esta perspectiva epistemológica apresente a politicidade da educação, ou seja, do papel social da educação, da escola e das deliberações possíveis da comunidade escolar.

\begin{abstract}
A raiz mais profunda da politicidade da educação se acha na educabilidade mesma do ser humano, que se funda na sua natureza inacabado e da qual se tornou consciente. Inacabado e consciente de seu inacabamento, histórico, necessariamente o ser humano se faria um ser ético, um ser de opções, de decisão. Um ser ligado a interesses e em relação aos quais tanto pode manter-se fiel quanto pode transgredi-la. É exatamente porque nos tornamos éticos que se criou para nós a probabilidade de violar a ética. (FREIRE, 2011, p. 108).
\end{abstract}

Para refletirmos sobre o papel social local dos docentes, temos que considerar que as práticas políticas que ocorrem na Escola Pública envolvem disputas pelo poder e, portanto, lidam com interesses antagônicos. (PARO, 2004). Como as ideias e interesses são diversos e distintos, precisamos entender que as decisões que acontecem no âmbito escolar, segundo a LDBEN, Lei n. ${ }^{\circ}$ 9.394/96, em seu Art. 14, devem fundamentar-se na gestão democrática, e seguir o princípio de que os profissionais da educação são os responsáveis por elaborar o projeto pedagógico da escola.

Partindo desses entendimentos podemos pensar sobre quais são os compromissos que o corpo docente têm com o contexto local onde a Escola está inserida. A Educação Escolar, garantida pela República, nos dá as possibilidades de definirmos em âmbito local os rumos que queremos com esse Projeto. Consequentemente essas definições moveram a comunidade escolar a definir as propostas que serão tomadas para que determinados interesses sejam contemplados. 
O exercício da cidadania dentro da Escola passa pela participação de professores, alunos e pais nos movimentos de discussões e tomadas de decisões sobre tudo o que for julgado importante, e assim, segundo Paro (2004) podemos buscar a integração das práticas políticas com as atividades administrativas. Entendemos que as práticas políticas possuem precedência sobre o âmbito administrativo da Escola, mas ressaltamos outrossim que antes das ações administrativas as definições aconteceram em definições políticas.

As definições políticas locais partem de interesses colocados em debate pelos indivíduos partícipes desse contexto. Não há possibilidade de o interesse seja contemplado postumamente sem ter passado pelo debate político anterior. A definição dos instrumentos organizados para garantir o debate político irá depender dos mecanismos incentivadores e viabilizadores organizados pelos dirigentes escolares juntamente com o conselho escolar, que reúne representantes da direção, dos professores, dos funcionários, dos alunos e dos pais dos alunos e da comunidade. No âmbito da Escola o Conselho é um órgão consultivo, deliberativo, normativo e fiscalizador. O Conselho Escolar possui importância fundamental na organização escolar, pois nesse âmbito local é que a Escola poderá segundo Paro (2004) ser um mecanismo de pressão e controle político sobre o Estado, em vez de ocorrer o inverso. As decisões democráticas se fundam no consenso dos grupos envolvidos, deixando de ser decisões verticais de uma cúpula ou de um indivíduo que se apropria do poder.

O contexto histórico brasileiro e a falta de compreensão das responsabilidades e possibilidades de atuação do cidadão no contexto local dão a impressão de que ele é refém do Estado. Há dificuldades de entendimento de que o Estado está para servir os interesses dos cidadãos e não deve acontecer o inverso. Pensar a escola como espaço de formação do cidadão é o espaço instituinte da República,

[...] por isso deve ser por ela mantida de modo a protegê-la contra as tentações demagógicas e sofísticas e em defesa da verdade e da liberdade que lhe deram origem. Para que isto se torne possível é necessário que se mantenha a escola com autonomia. Ela deve estar livre dos imperativos econômicos conjunturais; deve impedir que qualquer tipo de dogma esteja presente nas aulas; por fim, deve afastar a ameaça de que interesses particulares de alguns substituam o desenvolvimento das crenças de modo livre e autônomo pelos cidadãos. (MAAMARI, 2009, p. 22).

O Estado republicano e democrático se nutre das decisões consensuais resultante das decisões e deliberações dos cidadãos e das cidadãs. Essa opção é política e para se manter depende da autonomia dos cidadãos, logo precisa educá-los permitindo-lhes o desenvolvimento da autonomia por meio de possibilidades livres, sem intervenções externas.

A práxis política é garantia efetiva de poder dos cidadãos envolvidos em determinados setores da sociedade civil. Todos os cidadãos não terão condições de envolverem-se em todas as decisões acerca de políticas públicas sociais, mas parece-nos importante que aqueles que ali estejam inseridos tenham a responsabilidade ética e visão de que suas decisões devem ser consensuais de garantir o bem comum.

Azevedo (1997), fundamentando-se no entendimento de sociedade setorizada proposto por Durkheim, afirma que as sociedades modernas organizam-se através da existência de setores e que cada pessoa faz parte mais visceralmente de um dado setor devido sua atividade profissional específica, embora participem de inúmeros outros setores na 
condição de usuárias. Consequentemente as decisões sobre específica política pública sempre dependerá do envolvimento democrático de profissionais e usuários de cada setor.

Conforme Marques (2000) a luta local está propriamente na falta de entendimento dos processos de articulação de uma pedagogia compartilhada no âmbito da escola faz com que os processos desse setor da sociedade civil acabam por desconsiderar a pluralidade de entendimentos. Justamente nesse contexto é preciso haver um resgate da função da escola como mediadora dessas discussões, pois,

[...] administrar a escola é articular a unidade dela na pluralidade dos elementos que a compõem, dos processos que se desenvolvem e dos recursos que se exigem, pela dinâmica da ação comunicativa em que se cumprem as aprendizagens fundadas na linguagem com vistas ao entendimento amplo evitando-se o fechamento de cada componente nos próprios automatismos. Submete-se assim a gestão democrática do trabalho educativo e a direção administrativa da escola aos imperativos da racionalidade de múltiplas vozes [...]. (MARQUES, 2000, p. 105).

Cabe aos docentes, que são a parte integrante da Escola pública maiores conhecedores de suas estruturas, e que por serem servidores públicos são a parte menos rotativa do ambiente escolar, esclarecer e reforçar metodicamente a participação dos demais membros da comunidade escolar para que efetivamente as discussões e decisões sobre os interesses da própria Escola sejam garantidos democraticamente.

Para Azevedo (1997, p. 59), "[...] não se pode esquecer que a escola e principalmente a sala de aula, são espaços em que se concretizam as definições sobre a política e o planejamento que as sociedades estabelecem para si próprias, como projeto ou modelo educativo que se tenta por em ação".

A política educacional é uma totalidade maior, que irá ser o ponto de partida e o norteador para as definições do projeto político da escola, que contemplem as necessidades e objetivos locais. Mas as definições da política global (em nível de país) são resultantes de um consenso político que foi se afinando desde as primeiras discussões e definições do contexto local de cada escola. Portanto se existe uma política educacional, isso significa que ela antecede a ação administrativa. A política educacional nacional é resultante das discussões que partem dos diversos contextos locais, e que depois retorna novamente ao âmbito local.

Essa via de mão dupla reforça ainda mais a ideia de política como o envolvimento dos cidadãos acerca das decisões de seus próprios interesses. A garantia de consensos políticos demonstra a cadeia complexa de várias discussões que resultaram na concretude do que Azevedo (1997) designa de programa de ação política.

Azevedo (1997, p. 60) afirma que o referencial normativo global "[...] é construído pelas forças sociais que têm poder de voz e de decisão e que, por isso, fazem chegar seus interesses até ao Estado e à máquina governamental, influenciando na formulação e implementação das políticas ou dos programas de ação".

Segundo Veiga (2003) o caráter emancipatório do projeto-pedagógico enfatiza o processo de construção. Dessa forma as decisões resultantes do consenso "dos maiores interessados" pelo documento, são de ordem vertical invertida, pois partiram dos interesses e necessidades dos atores locais. 
Sob esta ótica, o projeto é um meio de engajamento coletivo para integrar ações dispersas, criar sinergias no sentido de buscar soluções alternativas para diferentes momentos do trabalho pedagógico-administrativo, desenvolver o sentimento de pertença, mobilizar os protagonistas para a explicitação de objetivos comuns definindo o norte das ações a serem desencadeadas, fortalecer a construção de uma coerência comum, mas indispensável, para que a ação coletiva produza seus efeitos. (VEIGA, 2003, p. 275).

Partindo das ideias apresentadas por Azevedo (1997) e Veiga (2003) podemos perceber o quanto a força democrática que emerge da própria escola, é o ponto de partida para as decisões que serão debatidas em caráter global para formular as políticas públicas e, por conseguinte, quando essas retornarem a escola em forma de documento, haverá novamente possibilidade de se retomar algumas ideias, afim de que realizar adequações e definir planos de ações, novamente com a presença da comunidade escolar.

\section{CONCLUINDO ESTA ELABORAÇÃO}

A participação social na elaboração, execução e avaliação das políticas públicas na área da educação e outras é condição fundamental para a formação, o exercício e a efetivação da cidadania plena da população de um país, estado ou município. A participação real na definição de políticas públicas, garantida em espaços democráticos, como conselhos, conferências, orçamento participativo, dentre outros, constitui-se como condição para a cidadania e este movimento igualmente afirma e democratiza os espaços e mecanismos de participação. A democracia é realizada na e pela participação individual e coletiva na vida societária.

As condições e os mecanismos de participação democráticos contribuem para a formação de uma cidadã e um cidadão democráticos, pois estes movimentos participativos constituem-se em espaços educativos na medida em que são realizados por relações humanas e construtores de políticas públicas. Os cidadãos e as cidadãs, defensores de uma ordem política democrática, podem constituir espaços, políticas e Estados democráticos e estes, por sua vez, contribuem para a formação de cidadãos democráticos, onde um requer a existência do outro, em um movimento recursivo, formando um círculo virtuoso.

Com a participação cidadão é possível construir a escola e o currículo como espaços democráticos. A participação na formulação do currículo escolar, independentemente do nível de educação, democratiza a escola como lócus formativo e o seu currículo. Um currículo democrático contribui na formação e educação democrática e também para uma sociedade democrática.

A Escola pode ser a potencializadora de novas ideias que partem de valores propriamente singulares e atentos às necessidades de cada espaço local. A autonomia pode garantir a originalidade das propostas consensuais dos cidadãos envolvidos em cada processo decisório. Para isso se faz necessária a desacomodação e a valorização da razoabilidade humana. Essa atitude propriamente autônoma desencadeia em possibilidades de delinear as intencionalidades efetivas do espaço educacional e democrático. 


\section{REFERÊNCIAS}

ABBAGNANO, Nicola. Dicionário de filosofia. 6. ed. Tradução Alfredo Bosi e Ivone Castilho Benedetti. São Paulo: WMF Martins Fontes, 2012.

AZEVEDO, Janete Maria Lins de. A educação como política pública. Campinas: Autores Associados, 1997.

BOBBIO, Norberto. A era dos direitos. Tradução Carlos Nelson Coutinho. Rio de Janeiro: Elsevier, 2004.

BOBBIO, Norberto. O futuro da democracia. Tradução Marco Aurélio Nogueira. São Paulo: Paz e Terra, 2011.

BRASIL. Constituição (1988). Constituição da República Federativa do Brasil: 1988. 18. ed. Brasília: Câmara dos Deputados, 2002. Série textos básicos, n. 27.

BRASIL. Lei Complementar n. ${ }^{\circ} 101$, de 4 de maio de 2000. Estabelece normas de finanças públicas voltadas para a responsabilidade na gestão fiscal e dá outras providências.

Disponível em: <http://www.planalto.gov.br/ccivil_03/leis/lcp/lcp101.htm>. Acesso em: 3 jun. 2014.

BRASIL. Lei n. ${ }^{\circ}$ 9.394/96, de 20 de dezembro de 1996. Estabelece as diretrizes de bases da educação nacional. Disponível em: <http://www.senado.gov.br/legbras>. Acesso em: 3 jun. 2014.

BRASIL. Lei n. ${ }^{\circ} 10.257$, de 10 de julho de 2001. Regulamenta os arts. 182 e 183 da Constituição Federal, estabelece diretrizes gerais da política urbana e dá outras providências. Disponível em: <http://www.planalto.gov.br/ccivil_03/leis/leis_ 2001 /110257.htm>. Acesso em: 3 jun. 2014.

CORRÊA, Darcísio. A construção da cidadania: reflexões histórico-políticas. Ijuí: UNIJUI, 1999. Coleção ciências sociais.

CORREAA, Darcísio. Estado, cidadania e espaço público: as contradições da trajetória humana. Ijuí: UNIJUI, 2010. Coleção direito, política e cidadania, n. 22.

FREIRE, Paulo. Pedagogia da autonomia: saberes necessários à prática educativa. 43. ed. São Paulo: Paz e Terra, 2011.

LOCKE, John. Segundo tratado sobre o governo. São Paulo: Martin Claret, 2002.

Coleção, A obra prima de cada autor.

MAAMARI, Adriana Mattar. A fundamentação filosófica da escola republicana. Contexto \& Educação, ano 24, n. 82, p. 59-81, jul./dez. 2009. Disponível em: <https://www.revistas .unijui.edu.br/index.php/contextoeducacao/article/viewFile/1012/767>. Acesso em: 19 maio 2014. 
MACHADO, Nílson José. Ensaios transversais: cidadania e educação. São Paulo: Escrituras, 1997.

MARQUES, Mário Osório. Aprendizagem na mediação social do aprendido e da docência. Ijuí: UNIJUI, 2000.

OCKHAM, Guilherme de. Brevilóquio sobre o principado tirânico. Tradução Luiz Alberto de Boni. Petrópolis: Vozes, 1988. Coleção clássicos do pensamento político.

OCKHAM, Guilherme de. Obras políticas. Tradução José Antônio de C. R. de Souza. Porto Alegre: EdiPUCRS, 1999.

PARO, Vitor Henrique. Gestão democrática da escola pública. São Paulo: Ática, 2004.

ROUSSEAU, Jean-Jaques. A origem da desigualdade entre os homens. Tradução Ciro Mioranza. São Paulo: Lafonte, 2012. Coleção Grandes clássicos da filosofia.

ROUSSEAU, Jean-Jaques. O contrato social. Tradução Paulo Neves. Porto Alegre: L\&PM, 2013. Coleção L\&PM POCKET, v. 631.

SCHIO, Sônia Maria. Hannah Arendt: história e liberdade - da ação à reflexão. Caxias do Sul: EDUSC, 2006.

TEIXEIRA, Elenaldo. Sociedade civil e participação cidadã no poder local. 1998. Tese (Doutorado) - Universidade de São Paulo, São Paulo, 1998.

VEIGA, Ilma Passos Alencastro. Inovações e projeto político-pedagógico: Uma relação regulatória ou emancipatória? Caderno Cedes, Campinas, v. 23, n. 61, p. 267-281, dez. 2003. Disponível em: <http://www.scielo.br/pdf/ccedes/v23n61/a02v2361.pdf.>. Acesso em: 20 maio 2014.

WEFFORT, Francisco. Por que democracia? São Paulo: Brasiliense, 1985.

\section{Notas}

\footnotetext{
${ }^{1}$ Doutor em Educação nas Ciências - UNIJUI. Professor Substituto na Universidade Federal da Fronteira Sul - UFFS, Campus Cerro Largo, RS e Professor nas Faculdades Integradas Machado de Assis - FEMA, Santa Rosa, RS.mariopuhl@yahoo.com.br.

${ }^{2}$ Mestre em Educação nas Ciências. Doutorando em Educação nas Ciências - UNIJUI. Professor no Instituto Federal Farroupilha, Campus Alegrete, RS. ajkrul@yahoo.com.br.

${ }^{3}$ Cabe ressalvar que este filósofo realiza uma crítica ao instituto da propriedade privada desenvolvida de maneira direta em A origem da desigualdade entre os homens. (ROUSSEAU, 2012).

${ }^{4} \mathrm{O}$ pensamento político liberal estabeleceu um critério claro para o exercício da cidadania, o de maioridade racional, ou seja, seriam cidadãos aqueles que houvessem alcançado do pleno uso da razão. Para Chauí (1997, p. 433) a maioridade racional é alcançada por aqueles “[...] que são independentes, isto é, não dependem de outros para viver. São independentes os proprietários privados dos meios de produção e os profissionais
} 
liberais. [...] A "maioridade" liberal refere-se, pois, ao homem adulto branco proprietário ou profissional liberal".

${ }^{5}$ Autores como Bobbio (2004), Lafer (1988) e Corrêa $(1999 ; 2010)$ trabalham o tema dos direitos humanos na perspectiva das gerações, eras ou fases. É uma compreensão linear ou cumulativa e sucessiva à qual estariam vinculados os direitos humanos. A perspectiva teórica da dimensão de direitos aponta para uma visão integral, engloba as diversas dimensões da condição humana (individual, social, política, econômica, cultural, ambiental, societária, da informação, da vida) e de suas diferentes atividades, interligando-se e estabelecendo uma relação biunívoca. Uma dimensão não ultrapassa a anterior e nem prescinde da outra. Uma dimensão requer a existência da outra.

6 "Segundo Alcméon de Cróton, é o perfeito equilíbrio das propriedades que constituem o corpo: a saúde; seu contrário é a monarquia, que é o predomínio de uma propriedade sobre a outra, o que constitui a doença. Segundo Epicuro, o perfeito equilíbrio e a perfeita correspondência de todas as partes ou os elementos do todo no infinito". (ABBAGNANO, 2012, p. 676).

${ }^{7} \mathrm{O}$ artigo 206 da Constituição Federal foi incluído na mesma através da Emenda Constitucional n. ${ }^{\circ}$ 19, de 4 de junho de 1998, após um amplo debate com a sociedade que buscava garantir o princípio da gestão democrática dos espaços de ensino. No entanto, este dispositivo constitucional ainda carece de regulamentação, que assim o prevê.

${ }^{8}$ Além das agendas políticas tradicionais dos sindicatos e partidos políticos, são trazidos à tona os temas e reivindicações das denominadas minorias (mulheres, índios, negros, homoafetivos, deficientes, etc.), a ecologia, a forma de produção energética (nuclear), a paz, dentre outras bandeiras de luta social.

${ }^{9}$ A Carta Magna brasileira de 1988 prevê um conjunto de instrumentos de participação popular, novos no ordenamento jurídico pátrio, incluídos por conta da participação da sociedade civil organizada durante a constituinte. Os mecanismos de participação são fruto da organização e participação social durante a elaboração da nova constituição federal, pois havia os mecanismos previstos no regimento interno da constituinte, que dentre outros é o da emenda popular. Podemos citar como instrumentos de participação social, dispostos da CF, os seguintes: os conselhos gestores de políticas sociais (artigo 194, inciso VII; artigo 198, inciso III; artigo 204, inciso II; artigo 205, caput); o plebiscito (artigo 14, inciso I); o referendo (artigo 14 inciso II); a iniciativa popular de leis (artigo 14, inciso III); a reclamação referente à prestação de serviços públicos (artigo $37, \S^{\circ}$ ); a provocação do inquérito civil (artigo 129, $\S 1^{\circ}$ ); a denúncia aos tribunais de contas (artigo 74, $\$ 2^{\circ}$ ); o mandado de injunção (artigo $5^{\circ}$, inciso LXXI); mandado de segurança (artigo $5^{\circ}$, inciso LXX).

Submetido em: 29/04/2016

Aprovado em: 18/07/2017 